\title{
Controvérsias e Disputas Simbólicas na Música Brega: o caso "tem gogó, querida?"
}

Controversies and symbolic disputes in the "you got vocal chops, honey?" affair

\section{Thiago Soares}

Professor do programa de Pós-graduação em Comunicação da UFPE.

\section{Pedro Alves Ferreira Júnior}

Mestrando do Programa de Pós-graduação em Comunicação da UFPE.

\section{RESUMO}

O artigo debate as controvérsias e disputas simbólicas na música brega de Pernambuco a partir de um desentendimento midiático protagonizado pelas cantoras Michelle Melo e Eliza Mell, em outubro de 2018, que ficou conhecido como o caso "Tem Gogó, Querida?". Utilizando-se de uma metodologia de inspiração latouriana e apropriada por Simone Pereira de Sá (2013 e 2014), propõe-se rastrear atores que performatizam seus gostos e valores no tocante à presença feminina na música brega. 0 episódio sugere que disputas morais em torno das performances de gênero e valorativas sobre o que significa cantar bem na música brega são fundamentais no espraiamento e na longevidade do episódio na cultura digital.

Pallavras-Chave: Música Popular; Disputas simbólicas; Performance de gosto; Estudos de Gênero; Cultura digital.

\section{ABSTRACT}

The article discusses the controversies and symbolic disputes in the brega music of Pernambuco from a media misunderstanding led by the singers Michelle Melo and Eliza Mell, in October 2018, which became known as the "You got vocal chops, 
honey?" affair. Using a latourian inspiration methodology appropriated by Simone Pereira de Sá (2013 and 2014), we propose tracking actors who perform their tastes and values regarding the female presence in brega music. The episode suggests that moral disputes over gender and evaluative performances about what it means to sing well in brega music are key to the reach and longevity of the episode in digital culture.

KEYWORDS: Popular Music; Symbolic Disputes; Taste performance; Gender Studies; Digital culture.

\section{RESUMEN}

El artículo analiza las controversias y disputas simbólicas en la música brega de Pernambuco a partir de un malentendido mediático dirigido por las cantantes Michelle Melo y Eliza Mell, en octubre de 2018, que se señaló como el caso "¿Tienes gogó querida?". Utilizando una metodología de inspiración latouriana y apropiada por Simone Pereira de Sá (2013 y 2014), se propone rastrear actores que realicen sus gustos y valores con respecto a la presencia femenina en la música brega. El episodio sugiere que las disputas morales sobre el género y las actuaciones evaluativas sobre lo que significa cantar bien en la música brega son clave para la difusión y la longevidad del episodio en la cultura digital.

PALABRAS-CLAVE: Música popular; Disputas simbólicas; Performance de gusto; Estudios de género; Cultura digital.

Michelle Melo e Eliza Mell são duas cantoras pernambucanas ligadas à música brega e conhecidas na cena local como expoentes de uma segunda geração do gênero musical ${ }^{1}$, grupo de artistas que fez sucesso principalmente na primeira metade dos anos 2000. A música brega consolidou-se em Pernambuco como um dos gêneros musicais mais característicos da periferia, especialmente no Recife e sua Região Metropolitana, trazendo consigo uma estética que perpassa não apenas a música, mas também dança, moda, lazer, consumo e estilo de vida (FONTANELLA, 2005). No sistema de produção midiática, a música brega opera em meio a uma gama de disputas simbólicas que atuam para engendrar valores e gostos dentro de contextos musicais específicos. Este trabalho se debruça sobre

1 Soares (2017) propõe uma tríplice categorização, baseada nos aspectos geracionais, para dar conta de uma falta de arquivo formal da música brega em Pernambuco. A primeira geração é

Dossiê Espaço Urbano e Imaginação Cultural - https://revistaecopos.eco.ufrj.br/

ISSN 2175-8689 - v. 22, n. 3, 2019

DOI: $10.29146 /$ eco-pos.v22i3.27422 
um desentendimento midiático protagonizado por duas cantoras de brega para apontar questões ligadas a valores consagrados nas performances na música popular a partir da formação de uma controvérsia em rede.

A polêmica tem início no dia 18 de outubro de 2018, quando Eliza Mell, apresentando-se junto com outras três cantoras do projeto Amigas do Brega ${ }^{2}$ no programa Tarde Legal da TV Nova Nordeste - um dos vespertinos dedicados ao brega na televisão pernambucana ${ }^{3}$-, é questionada pelo apresentador Marcos Silva sobre a existência de um conflito entre ela e Michelle Melo. Na ocasião, para "munir" a sua pergunta, o apresentador exibe o trecho de uma entrevista anterior em que Michelle Melo, que se intitula "rainha do brega", afirma que o malentendido decorre de um episódio em que ela (Michelle) teria sido acusada de mandar retirar os músicos emprestados num show de Eliza Mell porque esta teria se atrasado. Michelle Melo justifica que o atraso na apresentação teria feito chocar com o horário de seu próprio show, e que por isso ela "não pôde fazer nada a não ser chamar de volta meus músicos". A disputa, segundo Melo, foi parar no âmbito judicial após uma transmissão ao vivo no Instagram da opositora, em que Eliza a chama de "rainha da putaria", ironizando o título constantemente ostentado por Michelle ("rainha do brega") e a forma sexualizada na qual Michelle Melo sempre baseou suas performances e por meio da qual obteve grande notoriedade na cena brega do Recife.

20 projeto Amigas do Brega é formado por quatro cantoras que fizeram sucesso principalmente no início dos anos 2000, em Pernambuco, considerado de maior efervescência para a produção do "brega pop" (FONTANELLA, 2005), ritmo mais dançante, centrado na figura da cantora. A formação inicial do grupo era composta por Palas Pinho, Dany Myler, Dayanne Henrique e Isa Falcão, que foi substituída por Eliza Mell.

3 É preciso pontuar a importância que os programas de auditório da televisão pernambucana têm na cadeia produtiva da música brega. No início dos anos 2000 , o gênero musical ocupava um espaço nobre na programação dos atrativos televisivos locais, sempre no horário de almoço - uma tradição que se perpetuou em Pernambuco a partir de atrações como Muito Mais (TV Jornal), Tarde Legal (TV Nova Nordeste) e Tribuna Show (TV Tribuna), verdadeiros agenciadores do gênero na capital pernambucana. Por vezes, a televisão ultrapassa o papel de mediadora e passa, também, a tornar-se agenciadora no processo produtivo do brega no Recife. 0 jornalista Flávio Barra, quando foi apresentador do programa Tribuna Show, chegou a iniciar uma carreira como cantor de brega, lançando clipes e canções. Um episódio envolvendo assédio sexual de menores pelo apresentador Denny Oliveira, nos bastidores do programa Muito Mais, na TV Jornal do Commercio, em 2006, foi um dos motivos para ao fim de inúmeros programas de TV. 0 Tarde Legal, onde a polêmica que motiva este texto ocorre, é apresentado na TV Nova Nordeste, emissora de baixo alcance na Região Metropolitana do Recife, evidenciando ainda mais a importância da disseminação em rede do episódio através das redes sociais digitais. 
De volta a Eliza: no programa Tarde Legal, a polêmica segue com a negação das acusações de Michelle Melo. Em resposta, a cantora afirma que "não precisou da banda de ninguém", que não se atrasou e que a banda foi chamada quando ela já estava "com o pé no palco", acusando Melo de tentar fazê-la descumprir contratos. É nesse momento que, irritada, Mell questiona as habilidades de canto de Michelle Melo, tentando desqualificá-la, acima de tudo, pelo mérito musical. Eliza Mell ostenta sua educação formal em música, aprendida em igrejas evangélicas da periferia do Recife, ao dizer que, enquanto Michelle Melo não pudesse "conversar comigo sobre o que é uma clave de sol, uma clave de fá, uma clave de dó, cantar em vários idiomas, em qualquer tom", ela não precisaria "nem olhar para mim".

O trecho desta polêmica foi publicado no YouTube pela primeira vez no dia 20 de outubro de $2018^{4}$, dois dias após a sua exibição na televisão. 0 episódio mencionado aciona uma série de manifestações, entre diferentes atores sociais (artistas, produtores, celebridades e fãs), que nos direcionam ao debate sobre como uma atuação performática em rede age na forma de reconhecimento dos valores consagrados em determinados gêneros musicais. Ao apresentar os estudos de performance para compreender o potencial cênico de fenômenos midiáticos, Diana Taylor (2013) propõe encarar a performance como episteme, ou seja, camada formadora de repertórios e transmissora de conhecimentos centrados no corpo e transmitidos também a partir dele. De acordo com a autora, "aprendemos e transmitimos o conhecimento por meio da ação incorporada e da agência cultural" (TAYLOR, 2013, p. 17). As performances seriam atos de transferência que perpassam memória e formam tecidos e identidades sociais. A autora reforça a importância da teatralidade (ou seja, o inusitado da ação, a forma com que atores encenam seus dramas, o tom, o gestual e a própria narrativização da trama) no engajamento em torno dos acontecimentos midiáticos.

Toma-se o desentendimento entre as duas cantoras, portanto, como um agenciador performático na tessitura narrativa de acontecimentos em rede no contexto das disputas na música brega que migra da televisão para a internet e

4 Disponível em: $<$ www.youtube.com $/$ watch? $v=w j 9 h s b I l m E 0 \& t=79 s>$. Acesso em 5 de fevereiro de 2019.

Dossiê Espaço Urbano e Imaginação Cultural - https://revistaecopos.eco.ufrj.br/

ISSN 2175-8689 - v. 22, n. 3, 2019

DOI: 10.29146/eco-pos.v22i3.27422 
mesmo para os palcos durante apresentações das duas artistas. Culmina com a ampla disseminação do bordão “tem gogó, querida?”, frase proferida por Eliza Mell, ao final de sua explicação em tom raivoso e revanchista, que viraliza através da geração de memes e gifs amplamente disseminados nas redes sociais.

Como ferramenta metodológica para apreensão deste fenômeno, acrescentamos aos estudos de performance já mencionados a partir de Taylor, indicativos oriundos de Simone Pereira de Sá (2013 e 2014) acerca dos tensionamentos entre territorialidades digitais percebidas como sistemas culturais articulados em redes sociotécnicas. A autora percebe especificidades comunicacionais à luz do que propõe Bruno Latour (2000 e 2005) na Teoria AtorRede, para compreender como fenômenos culturais midiáticos que emergem nas periferias brasileiras (como as danças de passinho, os videoclipes amadores e as performances musicais registradas com celulares) engendram redes que conectam atores humanos e não-humanos, construindo elos e sobretudo controvérsias e disputas simbólicas em ambientes digitais.

0 procedimento metodológico proposto neste artigo conecta-se à maneira com que Pereira de Sá se utiliza de Latour para compreender as tessituras performáticas nas redes de música pop periféricas, elencando rastros que nos permitem identificar atores que catalisam controvérsias musicais, biográficas e mercadológicas travadas entre Michelle Melo e Eliza Mell. Acreditamos ser possível abrir possibilidades para dar conta de diferentes prismas de uma controvérsia, de sua complexidade e da maneira com que estas disputas agem nas performances musicais midiatizadas.

Como exercício metodológico, este artigo propõe-se mapear rastros que atuam numa polêmica midiática para formar uma rede sociotécnica, deslocando a interpretação do fenômeno dos objetos em si para como estes objetos "atuam", construindo assim também pistas sobre a performatividade de atores sociais em disputas simbólicas em rede. Este debate aproxima-se de uma pragmática do gosto, como define Antoine Hennion (2011), reverberando de que forma o gosto e como ele é performado - age para a formação de redes. Trata-se da contraposição à discussão trazida por Pierre Bourdieu (2007), que toma o gosto 
como algo de caráter mais estritamente ligado a classe social e, portanto, menos "moldável". Esta "virada" permite reconhecer os limites de uma abordagem sociológica de um fenômeno midiático que lida com atores sociais oriundos de periferias de grandes centros urbanos brasileiros.

A seguir, propomos articulações entre pragmática do gosto e a noção de cena musical para compreender como os espaços codificados por músicos, fãs e admiradores de gêneros musicais formam uma "cultura de afinidades" que incide em valores e engajamentos em rede.

\section{Performance de gosto em cena}

Quando falamos de cantoras de origem subalterna e periférica, mostra-se ainda mais importante considerar as relações sociais, mas também estéticas e especialmente aquelas impostas pelo meio aos atores de determinado gênero ou cena musical. Ao falar de cena musical, tomamos como base a discussão iniciada por Will Straw (2006), que, analisando cenário musical nos anos 1990, argumenta que as cenas podem ser pensadas como grupos demarcados por uma espacialidade cultural, onde coexistem diversas formas de práticas musicais que interagem entre si de múltiplas formas e compartilham referências estéticas de um ou mais gêneros. São espaços organizados onde "gostos e hábitos são perpetuados, apoiados por redes de instituições de pequena escala, como estabelecimentos comerciais e bares especializados" (STRAW, 2006, p. 13). Nessas cenas, "culturas de afinidade encontram coerência pela lenta elaboração de protocolos éticos que devem ser seguidos por aqueles que se movem por esses espaços" (idem).

Acrescentemos ao debate das cenas musicais a discussão da sociologia do gosto, em que Pierre Bourdieu (2007) argumenta que um campo é constituído por agentes em disputa que estão sempre envolvidos numa discussão sobre autoridade, legitimidade cultural e capital simbólico, sendo este último adquirido de maneira não institucionalizada pelo indivíduo. Pereira de Sá (2014), em suas considerações acerca da sociologia do gosto, ao comentar sobre as afetações e relações de amor de fãs com a música, contrapõe a perspectiva de Bourdieu de que 
o gosto cultural "vem de berço" e seria intrínseco à hierarquia de classes sociais à proposta de Hennion (2001), que toma como base a dimensão performática do gosto, além de ressaltar o papel de mediadores culturais e do caráter coletivo na formação do gosto.

Cultivar o gosto por um gênero ou estilo musical é um processo ou um evento - sempre inacabado, sempre em construção - onde as noções de afeto ou de paixão não podem ser colocadas de lado pelo pesquisador. Processo no qual actantes atualizam esses afetos e sensações a partir de mediações bastante heterogêneas - do álbum tocado no MP3 ao show ao vivo, por exemplo - que atuam como mediadores a fim de dar concretude à experiência musical de maneiras múltiplas (PEREIRA DE SÁ, 2014, p. 8).

Essas perspectivas nos interessam ao pensar a natureza das disputas acionadas a partir do episódio “tem gogó, querida?", especialmente a desqualificação de uma cantora, proposta por outra, durante uma controvérsia. Simone Pereira de Sá (2014) entende que "as redes são constituídas por materiais heterogêneos; e os atores (também chamados de actantes) definem-se como qualquer agente mediador que produza diferença - seja este um ator humano ou não-humano - na coletividade" (PEREIRA DE SÁ, 2014, p. 4). 0 que é defendido pela autora é que os fenômenos comunicacionais são compostos por uma ampla gama de interações que inclui humanos e, de forma não menos importante, elementos não humanos.

A autora argumenta que, no trabalho de um pesquisador, cartografar os rastros dos atores como mediadores na constituição das redes sociotécnicas é uma tarefa primordial. Isso porque, segundo Pereira de Sá, o próprio pesquisador "se torna, ele mesmo, mais um mediador ao identificar e fazer falar, através de seus textos, os diversos atores de uma rede, multiplicando os pontos de vista e as controvérsias" (PEREIRA DE SÁ, 2013, p. 36). Buscando, portanto, os rastros de atores em fenômenos midiáticos, sejam eles humanos e não-humanos, é possível analisar de que forma eles constituem coletivos performáticos, formam alianças e atuam como mediadores nas controvérsias em torno das cenas musicais. 
É sobre esta perspectiva que nossa investigação se debruça para tentar enfatizar a importância de visualizar os fenômenos em sua articulação dentro de uma rede. Nossa proposta é a de encarar a desavença midiática entre Michelle Melo e Eliza Mell como forma de deslocar as caixas-pretas ${ }^{5}$ para abrir novas possibilidades de discussão dentro da música brega de Pernambuco.

\section{Disputas de gênero e conveniências performáticas}

No início de sua carreira, na Banda Metade, Michelle Melo ganhou notoriedade pelo teor ultrarromântico e sexualizado de suas canções. Quase sempre com letras com duplo sentido, a cantora utilizava dos sussurros como estratégia vocal essencial para suas performances no palco. Suas apresentações também foram marcadas por coreografias e figurinos arquitetados para evocar um ideal feminino que remonta às divas da música pop estadunidense ${ }^{6}$. A própria Michelle constantemente afirma basear suas performances em cantoras do pop mainstream, como Britney Spears, Mariah Carey e mesmo Madonna, a quem é comparada de forma elogiosa. Ao falar pela primeira vez sobre a polêmica com Eliza Mell, Michelle Melo afirma que moveu uma ação criminal contra a cantora por ter sido chamada de "rainha da putaria" durante uma live no Instagram de Mell.

A forma jocosa como, supostamente, Eliza Mell insulta Michelle Melo diz respeito à postura adotada durante toda a carreira de Michelle, como a "mulherpiriguete" (SOARES, 2012, p. 8). Desde seu tom de voz, mais "baixo" e sussurrado, ela encena um ideal de mulher marcado pela sexualidade e pela reivindicação do prazer feminino. Soares argumenta que a piriguete, em contrapartida à figura do

5 "A expressão caixa-preta é usada em cibernética sempre que uma máquina ou um conjunto de comandos se revela complexo demais. Em seu lugar, é desenhada uma caixinha preta, a respeito da qual não é preciso saber nada, senão o que nela entra e o que dela sai. (...) Ou seja, por mais controvertida que seja sua história, por mais complexo que seja seu funcionamento interno, por maior que seja a rede comercial ou acadêmica para a sua implementação, a única coisa que conta é o que se põe nela e o que dela se tira" (LATOUR, 2000, p. 14).

6 "Algo que sempre chamou a atenção em Michelle, além da vivacidade em palco, é a forma como ela sempre afirmou dialogar com influências estéticas e performáticas provenientes de figuras consagradas da cultura pop. Desde o início da carreira, Melo foi intitulada, seja pela mídia pernambucana, a "Madonna do Brega", em referência à cantora estadunidense", (FERREIRA JÚNIOR, 2018, p. 2). 
cafuçu - por ele descrita como o homem viril, de camadas populares, ligeiramente rude e de grande competência sexual - é, muitas vezes, moralmente condenada.

\begin{abstract}
O que parece consensual é que piriguete é uma classificação de mulheres conhecidas por estarem na balada, geralmente solteiras, que escolhem com quem e quando querem "ficar", autossuficientes e que não se importam com a opinião alheia. A piriguete não costuma ser bem vista pelo público feminino e muitas vezes nem mesmo com o masculino. Taxada de vulgar, ocupa um espaço de identidade invisível, uma vez que reforça um deslocamento de um certo caráter moral e de um habitus socialmente inscrito. Trata-se de uma expressão bastante usada de forma cômica, em tom de brincadeira (SOARES, 2012, p. 5).
\end{abstract}

A própria Michelle afirma que, ainda menor de idade, iniciando a carreira no brega, precisou "inventar uma personagem" para tentar proteger-se dos olhares moralistas. "Michelle Melo é uma personagem. Como é que eu ia subir num palco, em frente a centenas de pessoas, e ia gemer? Precisei inventar Michelle Melo", diz a cantora ${ }^{7}$.

A partir desse episódio é possível observar diferentes encenações e valores na performance de gênero. O feminino, mesmo dentro de um ecossistema relativamente pequeno e de proximidade entre as diferentes atrizes sociais, é disputado pelas cantoras. Longe de tentar impor padrões estéticos distantes de dar conta da complexidade performática e de gênero no brega recifense, é curioso perceber como Eliza Mell, que teria chamado Michelle Melo de "rainha da putaria", no início de sua carreira também transitou entre a figura da mulher "oficial" e da própria piriguete. Em "Ânsia", o primeiro grande sucesso de Eliza Mell, ainda como vocalista da banda Brega.com, a cantora lamenta o amor prometido e não recebido em versos como "você jurou pra mim que vai me amar / eu não consigo mais te esperar / a ânsia foi maior e eu me entreguei a outro alguém", mas também celebra a satisfação sexual e o amor encontrado a partir do adultério, em trechos como "passamos uma noite de amor / nossos corpos se envolvendo foi tão bom / você jurou demais e não me deu amor/ o homem que eu encontrei me fez feliz / e me

7 A frase foi dita durante entrevista feita com a cantora durante o desenvolvimento da monografia "Bateu a química: A estética do videoclipe e o cosmopolitismo estético na cena musical brega do Recife" (FERREIRA JÚNIOR, 2017). 
abriu todas as portas do amor / me fez uma mulher realizada / e me tirou todas as dúvidas do amor".

Outra canção de Eliza Mell que encena uma mulher desviante dos padrões morais foi "Garota de Programa", em que a cantora diz que deixou de ser "uma qualquer", saindo do patamar considerado vergonhoso, moralmente errado e sem valor. Nessa canção, ela narrativiza os sofrimentos da vida como profissional do sexo e da forma como a personagem por ela encenada desliza entre performances de gênero ligadas ao feminino. "Deixei de ser garota de programa / deixei de ser uma qualquer / pois eu fiz com você loucuras na cama / e o telefone peguei quem sabe um dia ligar".

Percebe-se, portanto, que há um conjunto de conveniências performáticas nas encenações do feminino na música brega. Personagens como esposas, amantes, piriguetes, mulheres "da noite" e garotas de programa são constantemente acionadas nas narrativas das canções, em tramas ficcionais que podem ser acionadas discursivamente para chancelar endereçamentos mais moralistas ou disruptivos.

A seguir, debateremos especificamente a controvérsia em torno da voz das cantoras de brega, a partir dos valores evocados diante do que significaria "ter gogó" para artistas da indústria musical.

\section{O valor da voz na música brega}

A voz pode ser tomada como um dos elementos mais expressivos para o que Gumbrecht (2010) denomina como "produção de presença". Para o autor, a palavra "produção", em sua raiz etimológica (do latim producere) quer dizer, literalmente, 'trazer para diante', 'empurrar para frente', “então a expressão 'produção de presença' sublinharia que o efeito de tangibilidade que surge com as materialidades da comunicação é também um efeito em movimento permanente" (GUMBRECHT, 2010, p. 38). Ao perguntar se Michelle Melo "tem gogó", Eliza Mell põe em prova a própria capacidade corporal de Michelle Melo, para, assim, levantar um ponto que justificaria a deslegitimação de sua performance. 
Eliza reconhece que o valor de Michelle encontra-se sobretudo na dança, no gestual corporal e na sensualidade por ela evocada durante as apresentações. Ao mesmo tempo, questiona Michelle pelo "gogó", palavra que significa, na linguagem popular, "pomo de Adão", mas que como usada por Eliza se refere à garganta e às cordas vocais. Ser exímia cantora, exibir "dotes vocais", não é condição fundante para sucesso na música pop. Como constata Soares (2012), ao falar sobre shows de música pop e sobre o papel que a voz exerce na cultura midiática, há pontos que agregam valor às apresentações de cantoras que não se baseiam necessariamente no virtuosismo do canto, mas em uma infinidade de outros aspectos performáticos, como a dança, os gestuais e a própria presença cênica. Madonna é um exemplo sintomático. A "rainha do pop" é constantemente depreciada pela baixa qualidade vocal, ainda que bastante celebrada pela qualidade do espetáculo que protagoniza, a partir das coreografias, jogos cênicos e narrativas dispostas em cena.

\footnotetext{
Vai-se a um espetáculo de música pop com outras balizas estéticas (notadamente diferentes de um show de rock, de um show de rap, por exemplo), observando não necessariamente o virtuosismo do canto de um artista ou a dificuldade em torno da execução de um instrumento. Neste sentido, o ato performático de shows de artistas de música pop se configura num lugar em que as noções estritamente musicais são relativizadas. Os contornos delineiam a aparição de outros critérios valorativos para estes espetáculos. Neste sentido, shows de música pop apelam deliberadamente para o visual, para o cenário, a construção de universos encenados, diante de artefatos cênicos, figurinos, maquiagem e efeitos visuais (SOARES, 2012, p. 8).
}

A defesa de Wayne Koestenbaum (2001) é de que a voz sempre agregou valor e funcionou como forma de acionar autenticidades às performances musicais. Ao indagar o que as divas da ópera sentem no momento em que cantam e todo jogo biográfico e performático existente no ato de cantar, Koestenbaum investiga as relações entre gênero, sexualidade e emoção evocadas pela vocalidade da personagem feminina operística e discute sobre o elemento erótico da voz cantada. Como elemento feminino, a voz, na analogia proposta por Koestenbaum, nasce da similaridade anatômica entre as cordas vocais e a vagina, órgão sexual interno, que assim como a voz, é um fenômeno produzido dentro do corpo, omitido de ser visto pelos olhos, apenas sentido pelos ouvidos.

\section{Dossiê Espaço Urbano e Imaginação Cultural - https://revistaecopos.eco.ufrj.br/


$\mathrm{Na}$ análise da controvérsia entre as cantoras de brega, Eliza Mell parece se vincular, ao criticar a ausência de "gogó" de Michelle Melo, ao estrelato de figuras da música pop cujo valor é posto à prova a partir de sua extensão vocal. Esse tipo de tradição vocal tem seus primórdios na figura da diva da ópera, mas se consagra na indústria musical a partir de cantoras como Aretha Franklin e Etta James e, na música pop, Whitney Houston, Mariah Carey, Lady Gaga e Christina Aguilera.

Estas disputas sobre o que é cantar bem e "ter gogó" na música brega reverberou nas performances das duas cantoras. Na gravação do DVD das Amigas do Brega, grupo ao qual Eliza Mell faz parte, realizado no bairro de Nova Descoberta, periferia da Zona Norte do Recife, a cantora sobe no palco entoando o bordão que marca a polêmica. Ela canta "Ânsia”, o maior sucesso de sua carreira. Entretanto, muito mais que um apelo nostálgico, desta vez, Eliza tem algo a provar. Essa foi uma de suas primeiras aparições midiáticas após a entrevista no Tarde Legal e ela sabe que o palco, sendo seu, precisa provar que ela "tem gogó". Diferentemente das outras versões da canção encontradas no YouTube, Spotify ou mesmo nos álbuns da Banda Brega.com, ao longo da performance no DVD, ela estende seus vocais, brinca com a voz a cada verso e faz uso constante de melismas $^{8}$, como se reivindicasse para si o título de cantora virtuosa. É como se, assim, validasse sua autoridade de julgar os vocais alheios.

Ao cantar de forma virtuosa, Eliza Mell reivindica também autenticidade no âmbito da performance. Cantar bem significa ser autêntico em cena, com seu público e fãs. A noção de autenticidade é muito mais elástica e volátil que a simples dicotomia de "ter ou não ter" voz - que varia a depender do gênero musical ao qual se refere o fenômeno. Jeder Janotti Júnior (2008) afirma que “aquilo que é considerado autêntico em uma apresentação da cantora Madonna, por exemplo, a performance, a dança e os excessos físicos - seria considerado totalmente inapropriado a um cantor de blues" (JANOTTI JÚNIOR, 2008, p. 82). Mesmo dentro da tradição da música pop anglófona, os valores de autenticidade tendem a ser

8 Melismas são ornamentos vocais, constantemente utilizados em apresentações ao vivo, em que os cantores mudam a nota de uma sílaba enquanto ela está sendo cantada, estendendo a duração do trecho cantado. Essa técnica vocal é conhecida como uma espécie de "firula" usada desde, pelo menos, o século XIII, pelos padres ligados ao canto gregoriano na Europa medieval. 
moldáveis. No caso de Beyoncé, esse virtuosismo se dá, também, pela junção entre voz e gesto, focando no próprio esforço físico que a cantora é capaz de fazer enquanto canta e dança ao mesmo tempo (MATEUS, 2016).

Eliza também atribui seu valor de autenticidade ao expor conhecimentos do campo da educação musical, como "o que é uma clave de sol, uma clave de fá, uma clave de dó" e ao dizer que sabe cantar "em vários idiomas, em qualquer tom". Em seus shows, a cantora constantemente acrescenta a seu repertório, sucessos da música pop, como "I Have Nothing”, de Whitney Houston".

A polêmica protagonizada por Eliza Mell, naturalmente, age sobre sua performance em redes sociais digitais. A cantora altera a descrição de seu perfil na rede social Instagram e assume a identidade "rainha do gogó". Em dezembro de 2018, dois meses após a polêmica, é convidada para participar do programa Tribuna Show na condição de "julgadora" das qualidades vocais de artistas musicais ${ }^{10}$. Na ocasião, Eliza Mell elogia a cantora Beyoncé, que para ela é "uma professora". Ao falar sobre Luiza Ketilyn, outra cantora de brega do Recife mais nova que ela, implicitamente dá a entender que também é possível aprender a "ter gogó" e precisaria amadurecer a forma como canta. Percebe-se que, ao ser reconhecida como validadora das qualidades vocais de seus pares, Eliza Mell reconfigura o critério rígido utilizado com Michelle Melo na ocasião do desentendimento midiático.

No mesmo programa, ao falar do MC Troinha, um dos principais nomes do brega-funk no Recife11, Eliza hesita ao dizer que o cantor "não tem gogó", mas remedia os possíveis efeitos polêmicos de sua opinião ao revelar que, para o estilo de música cantado por Troinha, o gogó, esse elemento nebuloso e exclusivo, não é preciso. Troinha teria carisma, o que, segundo ela, seria suficiente para justificar seu valor como cantor.

9 Disponível em: <www.youtube.com/watch?v=8apeGwdIuPI>. Acesso em 7 de fevereiro de 2019. 10 Disponível em: <www.youtube.com/watch?v=raNhI4x7eYk>. Acesso em 7 de fevereiro de 2019. 11 Variação da música brega que aproxima o brega do funk, de onde saíram figuras como MC Loma e as Gêmeas Lacração, MC Sheldon e MC Elloco e Shevcenko. 0 brega funk é largamente composto por artistas que não precisam de grandes dotes vocais, cujo canto é marcadamente falado e coloquial. 


\section{Engajamento de fãs em redes}

É interessante debater também como a discussão entre Michelle Melo e Eliza Mell transita entre diferentes meios, já que foi iniciada na televisão durante apresentação musical; migrou para as "fofocas" entre os artistas do gênero musical nas redes sociais; voltou para a televisão nas referências das duas em programas locais; espraiou-se na internet, com a constante reapropriação por internautas dos bordões e "memes" produzidos pela discussão e em seguida, é reiterado na gravação de um DVD, que, por sua vez, foi publicado no YouTube antes mesmo de tornar-se mídia física. Os fãs, nesse caso, e a própria internet, são atores essenciais para a percepção do fenômeno do brega, e em especial a controvérsia à qual nos referimos neste trabalho, a partir de uma rede sociotécnica.

O desabafo midiático de Eliza Mell serve como o catalisador que desencadeia afetações e reações numa rede que extrapola até mesmo os ciclos sociais em que convivem os fãs, sejam eles de Michelle Melo ou de Eliza Mell. Dias depois da entrevista concedida por Eliza Mell na TV Nova Nordeste, Michelle Melo publicou uma foto no Instagram ${ }^{12}$ em que, apontando para a própria garganta, ela veste uma camiseta com a frase "gogó, tem gogó, kerida?". Na legenda, ela escreve: "'A paz vem de dentro de você mesmo. Não a procure à sua volta...' Quando a vida te der um limão, transforme em uma limonada \#Ficaadica", seguida pelas inúmeras hashtags e marcações de empresas que denotam as parcerias e patrocínios que ajudam Michelle a subsidiar sua carreira artística.

Na imprensa pernambucana, jornais locais repercutiram a polêmica e tentaram "explicar" aos leitores o que se passava, especialmente por causa da popularidade dos memes no Twitter e em outras redes sociais digitais. 0 portal OP9 se referiu à discussão entre as duas cantoras como “a 'arenga' mais quente do brega"13, enquanto o site LeiaJá limitou-se a dizer que "Michelle Melo debocha de

12 Em 5 de janeiro de 2019, a foto acumulava mais de 17 mil curtidas. Disponível em: $<$ www.instagram.com/p/Bp0005oHgQ1 >. Acesso em 5 de fevereiro de 2019.

13 Disponível em: <op9.com.br/pe/pop9/michelle-melo-rebate-eliza-mell-camiseta-afrontosa >. Acesso em 6 de fevereiro de 2019.

Dossiê Espaço Urbano e Imaginação Cultural - https://revistaecopos.eco.ufrj.br/

ISSN 2175-8689 - v. 22, n. 3, 2019

DOI: 10.29146/eco-pos.v22i3.27422 
cantora"14 omitindo o nome de Eliza ao noticiar a publicação da foto-resposta de Melo às acusações de Eliza Mell. Pela própria trajetória de Michelle Melo, a então "rainha do brega" na ocasião da polêmica, percebe-se como portais jornalísticos adotaram a versão de Michelle e omitiram a irrupção crítica de Eliza Mell.

O bordão citado por Eliza obteve notoriedade nacional principalmente a partir do Twitter, mas também por meio de grupos no Facebook voltados à comunidade LGBT, como o $\operatorname{LDRV}^{15}$, e do fórum Pandlr ${ }^{16}$. Tanto o grupo do Facebook quanto o fórum têm como prática performática a devoção às divas pop. As capas e fotos de perfil de ambas as ferramentas oscilam entre imagens de cantoras estadunidenses e os memes mais recentes e populares entre seus participantes.

Durante a já citada entrevista na qual Eliza responde ao apresentador sobre a polêmica entre as duas cantoras, ela afirma, sobre Michelle Melo, que "ela não tem fã, ela tem uma gangue, quadrilha, que ataca as pessoas na rede social". Sobre a relação entre fãs e engajamento acerca dos produtos culturais, Jenkins (2008) argumenta que os fandoms se constituem, principalmente, a partir de uma paixão cercada de disputas, que pode ser observada na forma como esses atores encenam sua performance de gosto por meio dos compartilhamentos, reapropriações ou mesmo nas reações dos haters ${ }^{17}$ acerca das aparições de artistas vistos como "inimigos" daqueles que são alvo de seus afetos.

Amaral (2012), ao debater o ativismo de fãs e haters, argumenta que através das "guerras simbólicas" entre fãs e antifãs existe uma questão de identidade que

14 Disponível em: <leiaja.com/cultura/2018/11/06/tem-gogo-querida-michelle-melo-debocha-decantora $>$. Acesso em 10 de fevereiro de 2019.

150 grupo foi criado em 2013, para postar tirinhas e memes produzidos sobre cantoras da música pop, principalmente de Lana Del Rey, cujo nome inspirou a sigla que intitula o grupo. Ao longo dos anos, o grupo tornou-se espaço para desabafos, pedir dicas e conversar sobre coisas do cotidiano. As histórias postadas são chamadas de "tours", e cada novo membro precisa ser aprovado por alguém que já esteja no grupo. Em seu auge, o LDRV chegou a contar com 1,2 milhão de membros. Em agosto de 2019, tinha mais de 434 mil.

160 fórum Pandlr é oriundo da rede social Orkut, e teve início como uma comunidade da rádio Jovem Pan dedicada à discussão de objetos da cultura pop, especialmente a música pop. Frequentemente, usuários do fórum republicam os vídeos de Eliza Mell e Michelle Melo, ironizando as duas cantoras e comparando o caso a desavenças famosas da cultura pop, como a rixa entre Taylor Swift e Katy Perry. Disponível em <pandlr.com/forum/30-pan/forum/topic/off-voceconhece-a-briga-que-gerou-o-bordao-tem-gogo-querida/>. Acesso em 15 de junho de 2019. 17 Personagens que se dedicam a odiar os artistas tanto quanto os fãs os amam. 
se revela no campo do discurso encenado pelos atuantes. Enquanto alguém que atua como não-fã simplesmente não liga para determinado artista, o antifã encontra sua distinção e constrói sua performance a partir do gosto "diferenciado" por desvalorizar o artista. Nesse ponto, segundo Amaral, ambos antifã e fã atuam de forma parecida.

\begin{abstract}
Fãs e antifãs são dois lados da mesma moeda. A fama de um determinado artista sempre causa o efeito de criação de odiadores (haters). Uma das hashtags que os fãs estavam utilizando tem a ver diretamente com isso: \#maisrespeitomenosinveja e está relacionada com duas categorias maniqueístas do comportamento humano. Onde quer que haja um fã, haverá um antifã ou hater, é parte da dinâmica. No Brasil, os torcedores/fãs de futebol são um exemplo sintomático. A diferença é que com o crescimento da popularização da internet no país, ambos os grupos (fãs e antifãs) tornam-se mais visíveis, bem como as possibilidades de arquivamento dessas discussões para pesquisas ou para objetivos mercadológicos. As apropriações e usos dessas redes como o Twitter amplificam esse tipo de engajamento (AMARAL, 2012, online).
\end{abstract}

$\mathrm{Na}$ controvérsia entre as cantoras de brega, Eliza Mell afirma não querer ouvir "um pio" sobre a desavença com Michelle Melo. Sua gestualidade, bem como as expressões faciais que utiliza, tornaram-se, assim como o bordão, fontes inesgotáveis de reapropriações na internet, seja por usuários da internet ou mesmo pela indústria da qual fazem parte das duas cantoras. Um exemplo é o cartaz da festa Bregalize (FIG 1.), realizada em dezembro de 2018, que teve as Amigas do Brega como uma das atrações. 0 frame do vídeo no momento em que Eliza diz não querer ouvir sequer "um pio" foi utilizado, ao fundo, para comunicar ao público que havia poucos ingressos restantes à venda. Outro exemplo da forma como Eliza Mell, como meme, se dissipou na internet é uma postagem também de dezembro de 2018, feita no perfil do blogueiro Hugo Gloss (FIG. 2), que acumula mais de 12 milhões de seguidores. No post, o bordão "tem gogó, querida?" é adaptado para elogiar a cantora estadunidense Miley Cyrus, em um vídeo gravado durante uma performance numa boate em Londres, no Reino Unido ${ }^{18}$.

18 Disponível em: <instagram.com/hugogloss/p/BrIqmmjBiaV>. Acesso em 5 de fevereiro de 2019. 


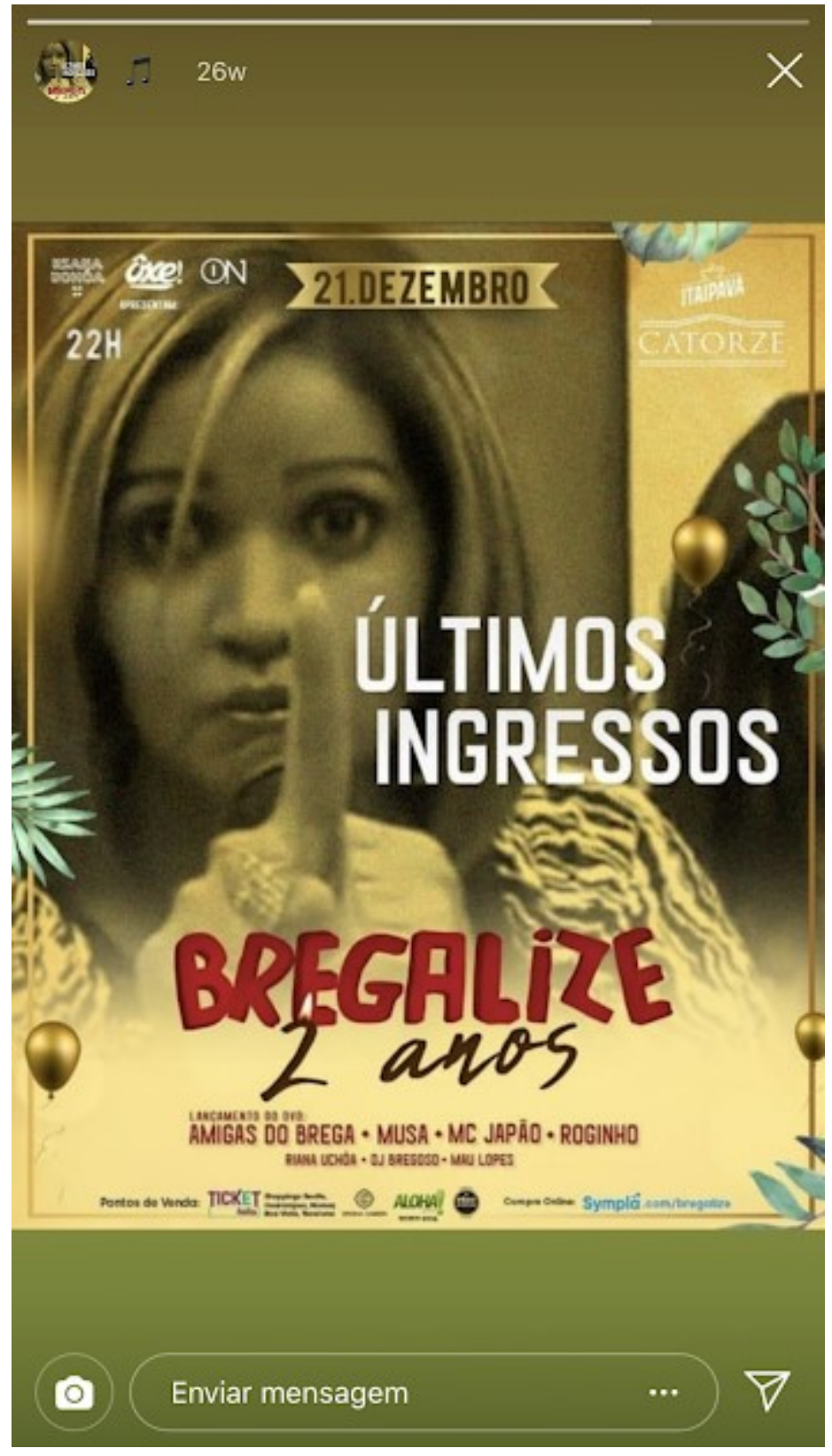

Fig. 1: Cartaz da festa Bregalize. Fonte: Instagram.

Dossiê Espaço Urbano e Imaginação Cultural - https://revistaecopos.eco.ufrj.br/

ISSN 2175-8689 - v. 22, n. 3, 2019

DOI: 10.29146/eco-pos.v22i3.27422 


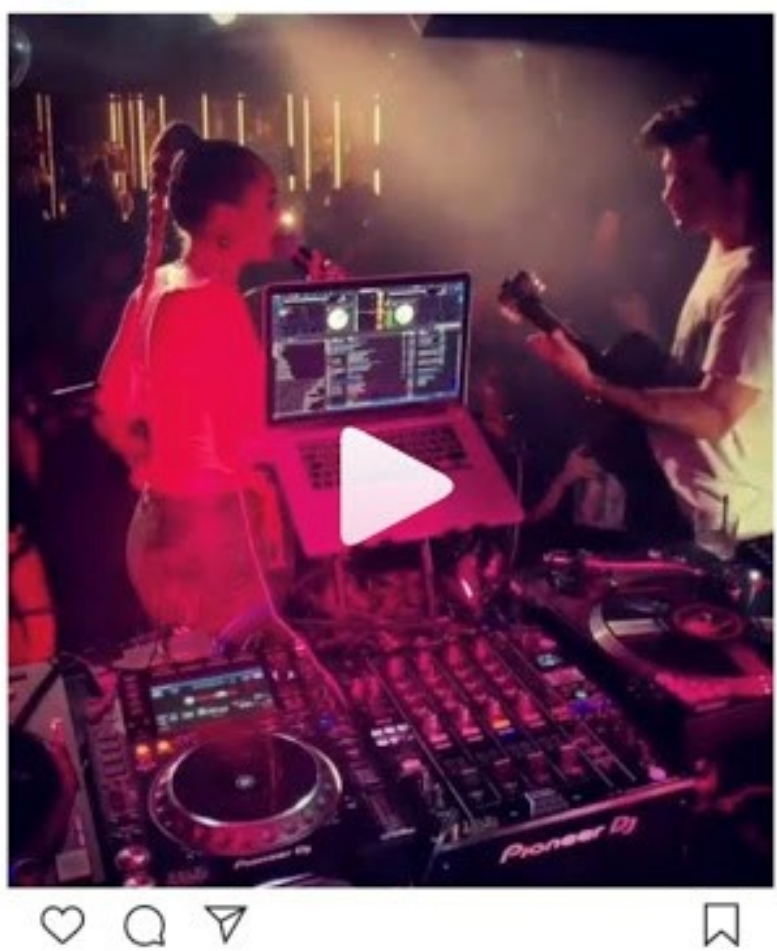

252.472 visualizaçōes

hugogloss Tem gogó, querida? Miley Cyrus provou que tem sim e arrasou em uma performance acústica do hit \#NothingBreaksLikeAHeart ontem (7), numa boate em Londres com Mark Ronson. Segundo a diva, a

apresentação foi no improviso. Essa sabe conversar sobre o que é uma clave de sol, de fá, de dó... kkkkk maravilhosa! \#repost @mileycyrus

Ver todos os 221 comentários

feholiveiran is is ds

hugosohares @alinelima_pst kkkkkks esse meme é dinminnu a Dranil nomu

Fig. 2: Postagem do blogueiro Hugo Gloss. Fonte: Instagram.

Para tratar das manifestações do gosto na internet, retomamos a noção de performance de gosto proposta por Antoine Hennion (2011), sob a luz da qual pode-se pensar, por exemplo, nos embates acerca dos produtos culturais em rede. Segundo o autor, o gosto constitui uma prática corporal, coletiva e instrumentalizada, cada vez menos simbólica e muito mais relacionada à percepção dos objetos com efeitos incertos. Por isso ele prefere utilizar o termo "vinculação".

Dossiê Espaço Urbano e Imaginação Cultural - https://revistaecopos.eco.ufrj.br/

ISSN 2175-8689 - v. 22, n. 3, 2019

DOI: $10.29146 /$ eco-pos.v22i3.27422 
O gosto, a paixão, as diversas formas de ligação não são dados primários, propriedades fixas dos amadores que podem ser simplesmente desconstruídos analiticamente. As pessoas são ativas e produtivas; elas transformam incessantemente tanto objetos e obras quanto performances e gostos. Insistindo no caráter pragmático e performativo das práticas culturais, a análise pode colocar em evidência a capacidade dessas pessoas de transformar e criar novas sensibilidades, em vez de somente reproduzir silenciosamente uma ordem existente (HENNION, 2011, p. 4).

Pode-se dizer que o episódio do "tem gogó, querida?" funciona como um agente causador de afetações nos fãs, antifãs e mesmo pessoas alheias à cena brega recifense. A forma passional como Eliza diz não querer "ouvir mais um pio" ou seu direcionamento ao questionar a capacidade vocal de sua colega de profissão quebram uma espécie de decoro midiático até então estabelecido para manter a cordialidade (ao menos publicamente) entre as duas. Essa afetação se materializa no compartilhamento de memes (FIG. 3) com o rosto e voz de Eliza nas redes sociais, em comentários descorteses nos perfis pessoais das cantoras ou mesmo no riso provocado pela exposição das duas em alcance potencialmente nacional, a partir da internet.

Os atores tomam parte na discussão, e, ao nela se engajarem, reverberam e ressignificam a seu modo, num processo sempre inacabado. A desavença não termina entre Eliza e Michelle, independentemente de suas atitudes posteriormente. No vídeo em que analisa o "gogó” de cantores, Eliza reconhece que "cada coisa que eu posto é um B.0.19", referindo-se às inúmeras polêmicas inferidas a partir de suas aparições midiáticas, sejam elas na televisão ou na internet. Mesmo quando não protagonizam diretamente aquilo que é tuitado, por exemplo, as duas cantoras participam daquilo que é falado.

Um exemplo de como a disputa travada entre as duas cantoras é causadora de afetos na internet, principalmente no Twitter (FIG. 4), é o do usuário @marcozgaspar, que recorre a uma performance de Eliza Mell anterior ao desenvolvimento da polêmica para atestar a capacidade vocal da cantora. Esse

190 termo B.O. refere-se a "boletim de ocorrência", mas nas práticas linguísticas de redes sociais digitais como o Twitter está atrelado à ideia de "treta" ou controvérsia.

Dossiê Espaço Urbano e Imaginação Cultural - https://revistaecopos.eco.ufrj.br/

ISSN 2175-8689 - v. 22, n. 3, 2019

DOI: $10.29146 /$ eco-pos.v22i3.27422 
caráter é reforçado por tuítes como o do cantor pernambucano Johnny Hooker (FIG. 3), por exemplo, que também se utiliza da polêmica envolvendo Eliza e Michelle para falar de sua agenda de shows, utilizando-se de uma certa autoironia (AMARAL, SOUZA e MONTEIRO, 2015). Ao mesmo tempo em que ostenta uma rotina intensa de shows, através da autoironia, Hooker brinca de questionar sua própria capacidade ao exaltar Eliza Mell.

\section{que musica fuderosa}

@marcozgaspar

\section{pra quem duvidou: eliza mell tem gogó mesmo}

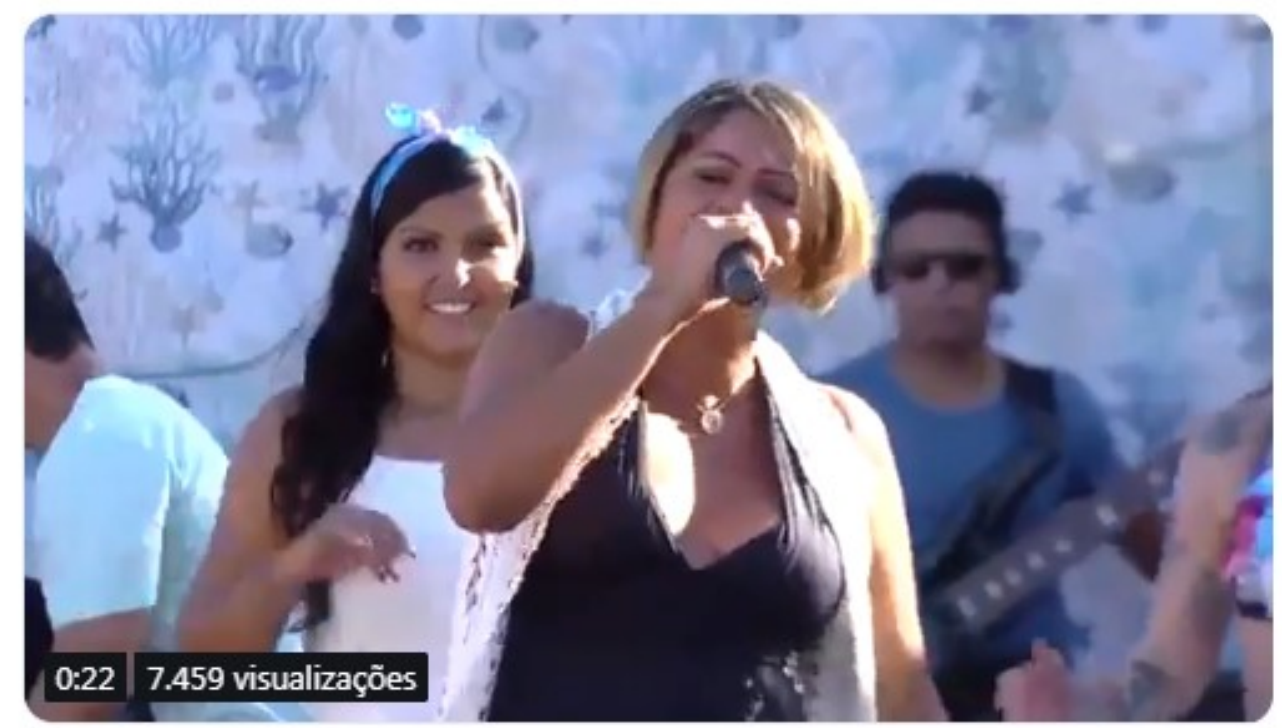

$14: 35$ - 24 de out de 2018

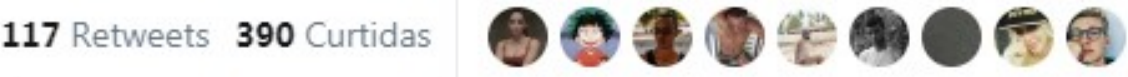

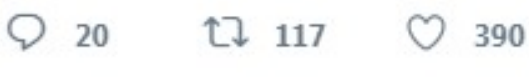

Fig. 3: Tuíte sobre o "gogó” de Eliza Mell. Fonte: Twitter. 
será q eu vou ter GOGÓ pra fazer 4 shows seguidos aqui em Salvador? Até hj só fiz no máximo 3 seguidos HELP ME AJUDE COM SEU GOGÓ ELIZA MELL

\section{1:07 - 10 de jan de 2019}

\section{Retweets 1.002 Curtidas}

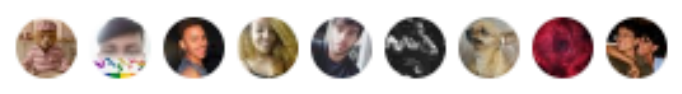

56

〔】 16

$1,0 \mathrm{mil}$

Fig. 4: Tuíte do cantor Johnny Hooker reapropriando a polêmica do "gogó". Fonte: Twitter.

\section{Considerações finais}

Ao longo deste artigo, tentamos explorar o debate acerca das performances de gosto e disputas de valor na música brega, a partir das manifestações agenciadas pelos discursos de duas cantoras expoentes do gênero musical. Ao mapear os atores envolvidos nas disputas simbólicas protagonizadas pelas artistas na cena musical recifense, nos interessa abrir possibilidades de discussão como caixas-pretas, repletas de questões a serem desenvolvidas no debate sobre valores nas cenas e gêneros musicais.

Como situa Diana Taylor (2013, p. 27), “obediência cívica, resistência, cidadania, gênero, etnicidade e identidade sexual são ensaiados e performatizados diariamente na esfera pública". No caso específico de Eliza Mell e Michelle Melo, cabe sublinhar as disputas em torno das performances de gênero e de sexualidade que reverberam padrões de comportamento e de moralidade em torno das mulheres oriundas das periferias. Ressaltamos que esta disputa que se dá sobretudo no campo ficcional - ou seja, nas personagens encenadas nas canções e 
nos videoclipes - espraia-se constantemente na biografia das cantoras, operando sobre estigmas em torno de mulheres pobres da periferia, seus estilos de vida e tomadas de posição em torno de decisões no campo afetivo.

Destacamos que ao tratar uma controvérsia midiática a partir da formação de redes sociotécnicas que engendram performances de gosto e valores, tenta-se abrir fenômenos midiáticos para a complexidade e para a incerteza, posicionando os intérpretes - e sua memória e articulação - como centrais para a reconstituição dos rastros e possibilidades interpretativas.

\section{Referências bibliográficas}

AMARAL, A. Dialogando sobre mobilizações de fãs e antifãs. Blog adriamaral.com. Disponível em: <palavrasecoisas.wordpress.com/2012/01/21/faseantifa >. Acesso em 5 de fevereiro de 2019.

AMARAL, Adriana; BARBOSA, Camila; POLIVANOV, Beatriz. Subculturas, re(a)presentação e autoironia em sites de rede social: o caso da fanpage "Gótica Desanimada" no Facebook. Revista Lumina, Juiz de Fora, v.9, n.2, 2015. Disponível em: <lumina.ufjf.emnuvens.com.br/lumina/article/view/481>. Acesso em: 13 de junho de 2019.

ARAÚJO, Paulo César de. Eu não sou cachorro, não: música popular cafona e ditadura militar. Rio de janeiro: Record, 2010. 7a. Ed.

BOURDIEU, Pierre. A distinção: crítica social do julgamento. São Paulo: Edusp, 2007.

FERREIRA JÚNIOR, Pedro Alves. "Madonna do Brega" - Cosmopolitismo estético na performance de Michelle Melo. In: Congresso Brasileiro de Ciências da Comunicação (Intercom), 2018. Joinville. Anais Eletrônicos. Disponível em: <portalintercom.org.br/anais/nacional2018/resumos/R13-0202-1.pdf>. Acesso em 7 de fevereiro de 2019.

FONTANELLA, Fernando. A estética do brega: cultura de consumo e o corpo nas periferias do Recife. Recife: Universidade Federal de Pernambuco. Dissertação de mestrado - Programa de Pós-Graduação em Comunicação, 2005.

GUMBRECHT, Hans Ulrich. Produção de Presença: $O$ que o Sentido não consegue transmitir. Rio de Janeiro: Ed. Contraponto, 2010. 
HENNION, Antoine. Music Lovers. Taste as performance. In: Theory, Culture, Society 18. 5 (2001) 1-22.

. Music and Mediation: Towards a new Sociology of Music. In: The Cultural Study of Music: A Critical Introduction. M. Clayton, T. Herber t, R. Middleton eds. London: Routledge, 2002.

. Pragmática do Gosto. Desigualdade \& Diversidade - Revista de Ciências Sociais da PUC-RJ, no 8, jan/jul, 2011, pp. 253-277.

JANOTTI JUNIOR, Jeder Silveira. Autenticidade e gêneros musicais: valor e distinção como formas de compreensão das culturas auditivas dos universos juvenis. Revista Ponto-e-Vírgula, v. 4, 2008.

JENKINS, Henry. Cultura da convergência. São Paulo: Aleph, 2008.

KOESTENBAUM, Wayne. The queen's throat: Opera, homosexuality, and the mystery of desire. New York: Poseidon Press, 1993.

LATOUR, Bruno. Ciência em ação: como seguir cientistas e engenheiros sociedade afora. São Paulo: UNESP, 2000.

- Reassembling the Social. An Introduction to Actor-Network Theory. U.K.,Oxford Univ. Press, 2005.

MATEUS, Suzana Maria de Sousa. Okay, ladies, now let's get in formation: o dia em que Beyoncé pautou questões raciais no Super Bowl 50. Congresso Brasileiro de Ciências da Comunicação (Intercom), 2016. Caruaru. Anais Eletrônicos. Disponível em: <portalintercom.org.br/anais/nordeste2016/resumos/R52-1469-1.pdf>. Acesso em 7 de janeiro de 2019.

PEREIRA DE SÁ, Simone. Em busca dos rastros e das materialidades das cenas virtuais. In: Congresso Brasileiro de Ciências da Comunicação, 2013. Manaus. Anais Eletrônicos. Disponível em: <intercom.org.br/papers/nacionais/2013/resumos/R8-1420-1.pdf>. Acesso em 7 de fevereiro de 2019.

. Contribuições da Teoria Ator-Rede para a Ecologia Midiática da Música. Contemporanea-Revista de Comunicação e Cultura (2014): 537-555.

SOARES, Thiago. 2012. Conveniências performáticas num show de brega no Recife: Espaços sexualizados e desejos deslizantes de piriguetes e cafuçus. In: Revista Logos, Comunicação e Entretenimento: Práticas Sociais, Indústrias e Linguagens. Rio de Janeiro, 2012. Disponível em: 
<eyesonrecife.files.wordpress.com/2012/06/soares_conveniencias_performaticas. pdf $>$. Acesso em 7 de fevereiro de 2019.

. "Ninguém é perfeito e a vida é assim": A música brega em Pernambuco. Recife: Editora Outros Críticos, 2017.

STRAW, Will. Communities and Scenes in Popular Music. In: GELDER, Ken \& THORNTON, Sarah. (org). The Subcultures Reader. Londres: Routledge, 1997.

. Scenes and sensibilities. In: E-Compós. Brasília: Compós, n. 6, 2006.

Disponível em: <public.journals.yorku.ca/index.php/public/article/view/30335>. Acesso em 7 de fevereiro de 2019.

TAYLOR, Diana. $O$ arquivo e o repertório - performance e memória cultural nas Américas. Belo Horizonte: UFMG, 2013. 